\section{Microcomputer-controlled Freezing, Data Acquisition and Analysis System for Cold Hardiness Evaluation}

\author{
Robert L. Wample, Guy Reisenauer, and Andy Bary \\ Washington State University, Irrigated Agriculture Research and \\ Extension Center, P. O. Box 30, Presser, WA 99350
}

\section{Fred Schuetze \\ Washington State University Technical Services, Pullman, WA 99164}

Additional index words. grape, Vitis, exotherm analysis, supercooling, winter hardiness, mites, aphids, Diuraphis

\begin{abstract}
A computerized system capable of controlling the freezing rate and collecting, storing, and analyzing data from multiple samples to determine their freezing point using low-temperature exotherm analysis is described. Details include electrical diagrams of modifications to the multiplexer/amplifier interface to provide additional signal amplification and permit control of the freezer's compressor. Computer software is described that permits variable temperature decline rates. Data analysis consists of a program in " $C$ " that sequentially compares each data point in a low-temperature exotherm profile. Low-temperature exotherms are identified by a user-specified minimum differential between sequential data points. Examples of exotherm output and data analysis are given.
\end{abstract}

Burke et al. (1976) and Levitt (1980) described several methods to evaluate the cold hardiness of various organisms. The first method was-to observe the extent of injury or survival of an organism after a naturally occurring low-temperature episode. Although such an event is the ultimate test of hardiness at that moment, naturally occurring low-temperature events are unpredictable, and the variability of other environmental factors can significantly influence an organism's survival. Other methods evaluate injury occurring at controlled temperatures. Levitt (1980) described most of these techniques as well as their strengths and weaknesses.

Freezing of organisms or tissues that supercool can be measured by differential thermal analysis (DTA) (Burke et al., 1976; McLeester et al., 1969). DTA detects the heat of fusion released as supercooled water in the organism freezes. The temperature at which this occurs, referred to as low-temperature exotherm (LTE), marks the lethal temperature for these organisms that are killed when they freeze (Quamme, 1974).

Thermal analysis has been enhanced by use of personal microcomputers in freezer

Received for publication 8 June 1989. Hort/LA Paper no. 89-17. Project no. 0519. Washington State Univ., College of Agriculture and Home Economics Research Center, Pullman, WA 99164. We acknowledge financial "support from Chateau Ste. Michelle; a subsidiary of U.S. Tobacco, and research support from the College of Agriculture and Home Economics to Robert L. Wample. Trade names have been used to simplify information. No endorsement is intended. The cost of publishing this paper was defrayed in part by the payment of page charges. Under postal regulations, this paper therefore must be hereby marked advertisement solely to indicate this fact. control and data acquisition. Ashworth et. al. (1981) used a data-logger to moniter multiple copper-constan thermocouples for evaluating the cold hardiness of Prunus flower buds. Thermocouples are relatively insensitive. and usually must be inserted into the organism (tissues or organs) to permit exotherm detection. This may be impossible with very small samples and may influence the ice nucleation point, thereby giving an inaccurate estimate of the killing temperature (Quamme, 1974). Andrews et al. (1983) first reported the use of thermoelectric modules connected to multichannel chart recorders for analysis. More recently, Wolf and Pool (1986) reported the use of thermoelectric modules and an IBM-PC to monitor the hardiness of Vitis buds.

Table 1. Low-temperature exotherm analysis by software program "EXOSEP" at 100- and 50-mV threshold levels for 'Cabernet Sauvignon' (CS), 'Chenin Blanc' (CB), and 'Concord' (CD) grape buds, and the estimated $\mathrm{LT}_{50}$ at each threshold value.'

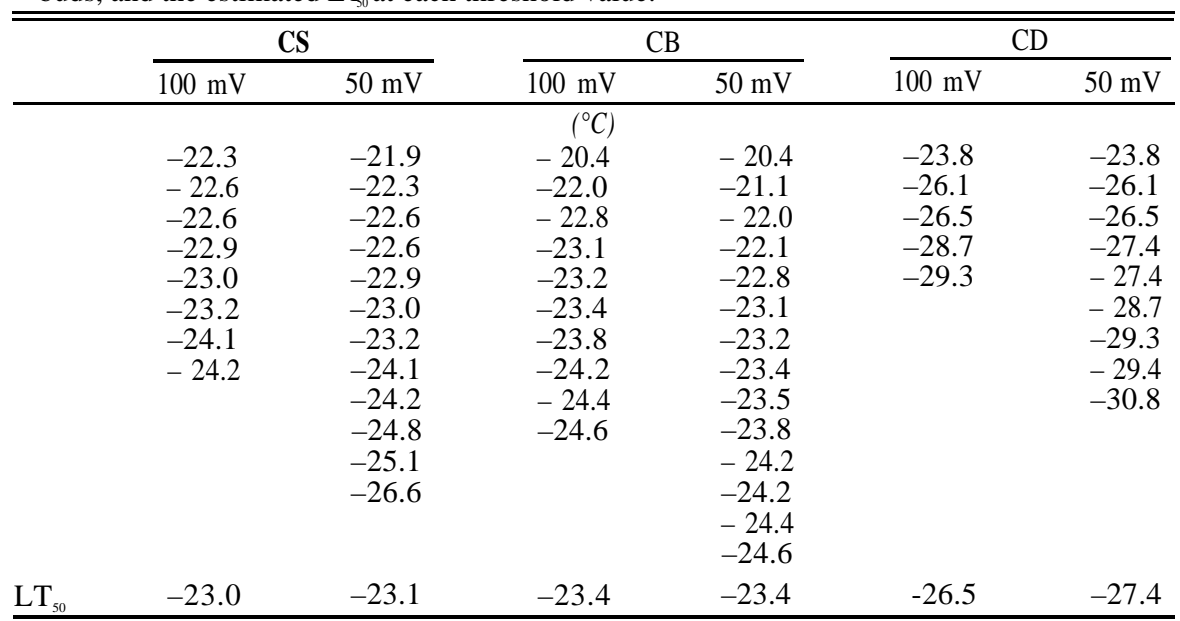

${ }^{2}$ Each value represents an exotherm as determined by either a 50 - or $100-\mathrm{mV}$ or greater difference between two sequential data points for the exotherm profile. voltage and, therefore, prevents signal "carryover" between channels. The TEMs are installed in a box constructed of 62-mm-thick styrofoam with outside dimensions of $38 \mathrm{x}$ $38 \times 26 \mathrm{~cm}$ (TEM chamber) to minimize the effects of temperature gradients in the freezer. The box was placed inside of a programmable freezer (Scientemp, Adrian, Mich.).

The freezer's control selection switch was modified (Fig. 1B), providing computer control with a BASIC program (COLLECTH) using imputs from temperature-monitoring circuits (Figs. 1A, 2A), temperature transducers in the freezer and TEM chambers (Fig. 1A), and a user-selected rate of temperature change.

The refrigeration control interface consists of a buffered parallel interface card residing in

Our objectives were to develop: 1) a computer-controlled freezing system that would provide flexibility in the programming of temperature profiles during freezing tests; 2) a computer-assisted data acquisition and storage system capable of handling many samples and that would lend itself to computer-aided data evaluation to minimize analysis times.

The configuration of the LTE analysis system is represented in Fig. 1. An IBM-PC XT equipped with a Dash-8, 12-bit high-speed analog to digital converter (Metrabyte, Stoughton, Mass.) was connnected to an EXP16 (Metrabyte) multiplexer/amplifier interface. Five additional EXP-16 boards can be connected, allowing up to a total of 80 inputs. The EXP-16 was modified to provide additional amplification (gain $=10$ ) (Fig. 2B) of the signal from the thermoelectric modules (TEM) (Model CP1.4-127-045L, Melcor, Trenton, N. J.) above the standard . gain of 1000 on the EXP-16. The 'X10 Amp' includes a noise-filtering feature that consists of a bandwidth limitation to $7 \mathrm{~Hz}$ at the 3 $\mathrm{db}$ point as per the AD521 manufacturer's suggested circuit, and imposes a 2.5 -see delay between sampling individual TEM thannels. The $2.5 \mathrm{sec}$ is required before the X10 amplifier's output corresponds to the TEM

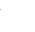


A

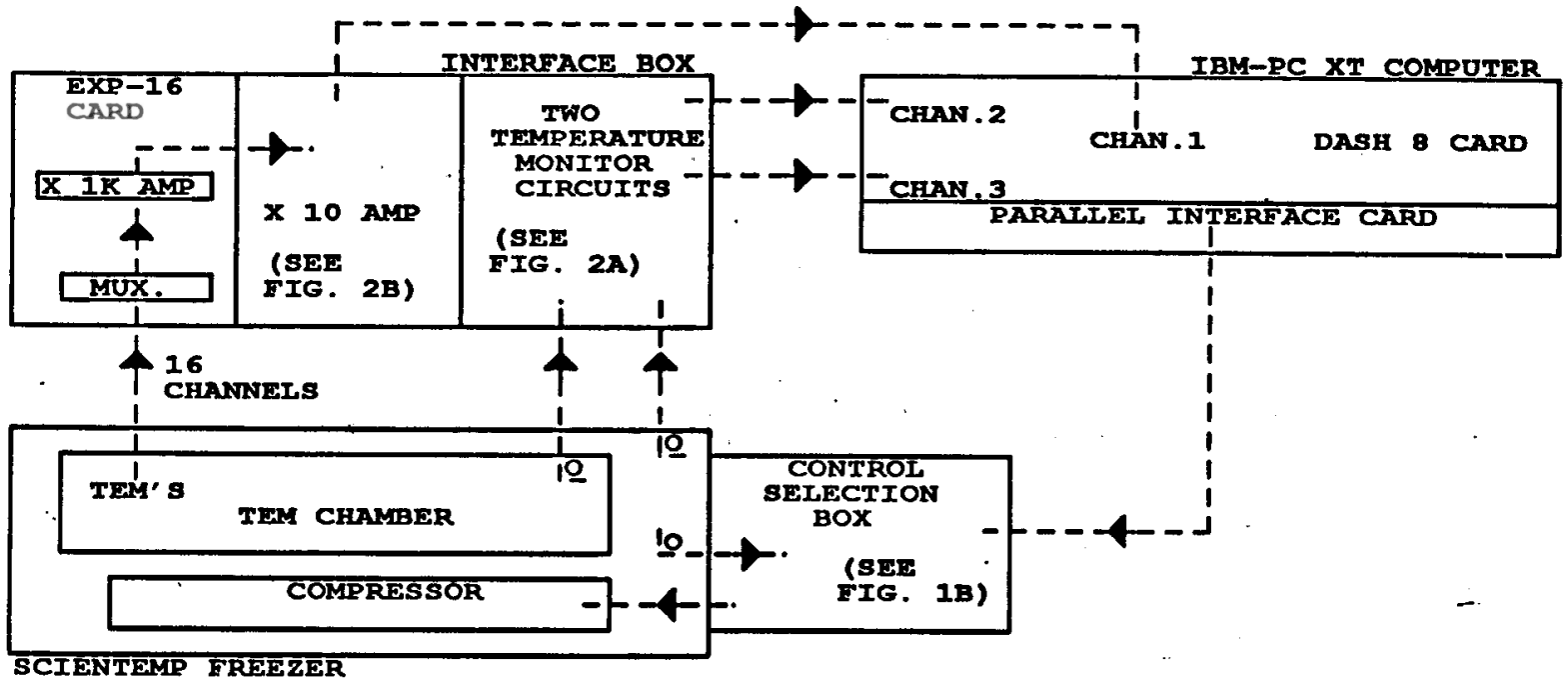

B

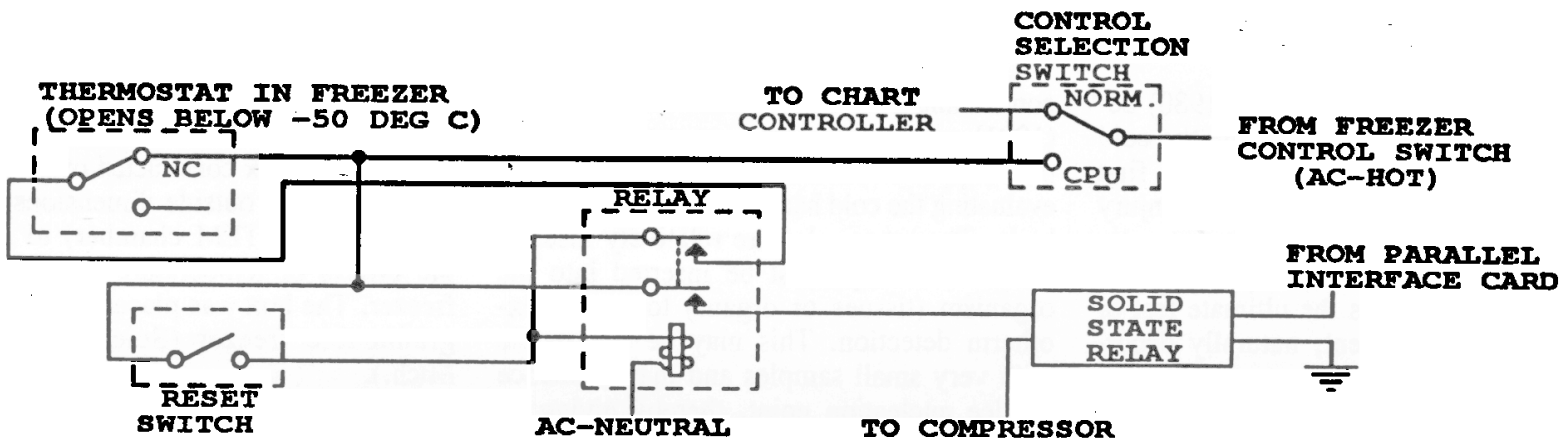

Fig.1. (A) Diagram of the principal components of a low-temperature exotherm analysis: an IBM-PC XT with a Dash-8 parallel interface card; an EXP16-multiplexer/amplifier interface card, modified with an additional X10 amplifier two temperature monitoring circuits; Scientemp freezer with a modified control selection box; thermoelectric module (TEM) chamber constructed of 62-mm-thick styrofoam; temperature transducers located in the freezer compartment and TEM chamber. Output from the TEMs and temperature transducers is via the EXP-16 to the Dash-8/IBM-PC XT(B) Electronic modifications to the freezer control selection box to allow computer control of the freezer compressor.

the computer and a control selection box fitted on the freezer' front panel (Fig. 1). Also housed in the control selection box is a fail-safe circuit using a thermostat in the refrigeration chamber. The thermostat-turns the compressor off once the temperature reaches $-50 \mathrm{C}$ and prevents the compressor from running continuously in the event of a program failure. The control selection switch also allows for manual control of the temperature.

The COLLECTH program for temperature control and data acquisition (available upon request) requires the following inputs: 1) number of TEM channels to be monitored, 2) desired sampling interval, 3) starting temperature, 4) ending temperature, and 5) experimental time interval., Up to eight sequential temperature steps can deprogrammed, including rates of temperature decline and plateau times. A linear temperature decline profile for the TEM chamber temperature (Fig. 3, line A) is shown at a rate of $4 \mathrm{C} / \mathrm{hr}$ from 0 to $-40 \mathrm{C}$. Figure 3 (line B) shows a temperature profile for which the following steps were programmed: 1) 0 to $-10 \mathrm{C}$ in $2.5 \mathrm{hr} ; 2$ ) $-10 \mathrm{C}$ for $2 \mathrm{hr} ; 3)-10$ to $-20 \mathrm{C}$ in $3 \mathrm{hr} 4$ ) $-20 \mathrm{C}$ for $2 \mathrm{hr} ; 5)-20$ to $-40 \mathrm{C}$ in $5 \mathrm{hr}$; and 6 ) held at $-40 \mathrm{C}$ for 2 $\mathrm{hr}$. The length of time the program can run is limited only by the disk storage space available for data collection. The maximum rate of temperature change depends on the freezer being used and the heat transfer rate of the TEM chamber.

Two data files, temperature data and exotherm data, are collected and stored on the computer's hard disk using a date-time file naming system [i.e., D8902121.500 indicates a data file (D) made 1989 (89), February (02) 12 (12) starting at 1500 HR (1.500)]. The temperature data are recorded to two decimal places and represent the temperature of the TEMs in the TEM chamber. Disk storage space is conserved by multiplying the temperature values by 100 . A typical experiment with 15 TEMs (channels), a 30-second sampling interval, and a linear temperature decline from 0 to $-40 \mathrm{C}$ results in $\approx 1000$ temperature points and 1000 data points (millivolt) for each TEM. The data (exotherm) files are analyzed using a program (EXOSEP) written in "C". The EXOSEP program also identifies the temperature at which each exotherm occurs. This EXOSEP program allows the user to select the exotherm threshold (the minimum TEM voltage difference between any two sequential. points), and thus vary analysis sensitivity. The separated data files are stored to disk. The temperature files are imported to a spreadsheet (VP Planner Plus, Paperback Software International, Berkeley, Calif.) and divided by 100 to convert back to decimals. Imported data files can then be plotted against the temperature file to produce an exotherm profile (Fig. 4 A and B).

Dormant grape buds (Vitis labruscana CV. Concord, V. vinifera cvs. Cabernet Sauvignon and Chenin Blanc) were selected from fieldgrown plants located at the Irrigated Agriculture Research and Extension Center, Prossser, Wash., in 1989 and 1990. The buds were selected from the third to the eighth nodes and prepared according to Andrews et al. (1984). Five to 10 buds were placed in $45 \times 45 \times$ 16-mm-deep plastic boxes lined with 2-mmthick foam and modified by cutting two small slots in one. side to allow the electrical leads 


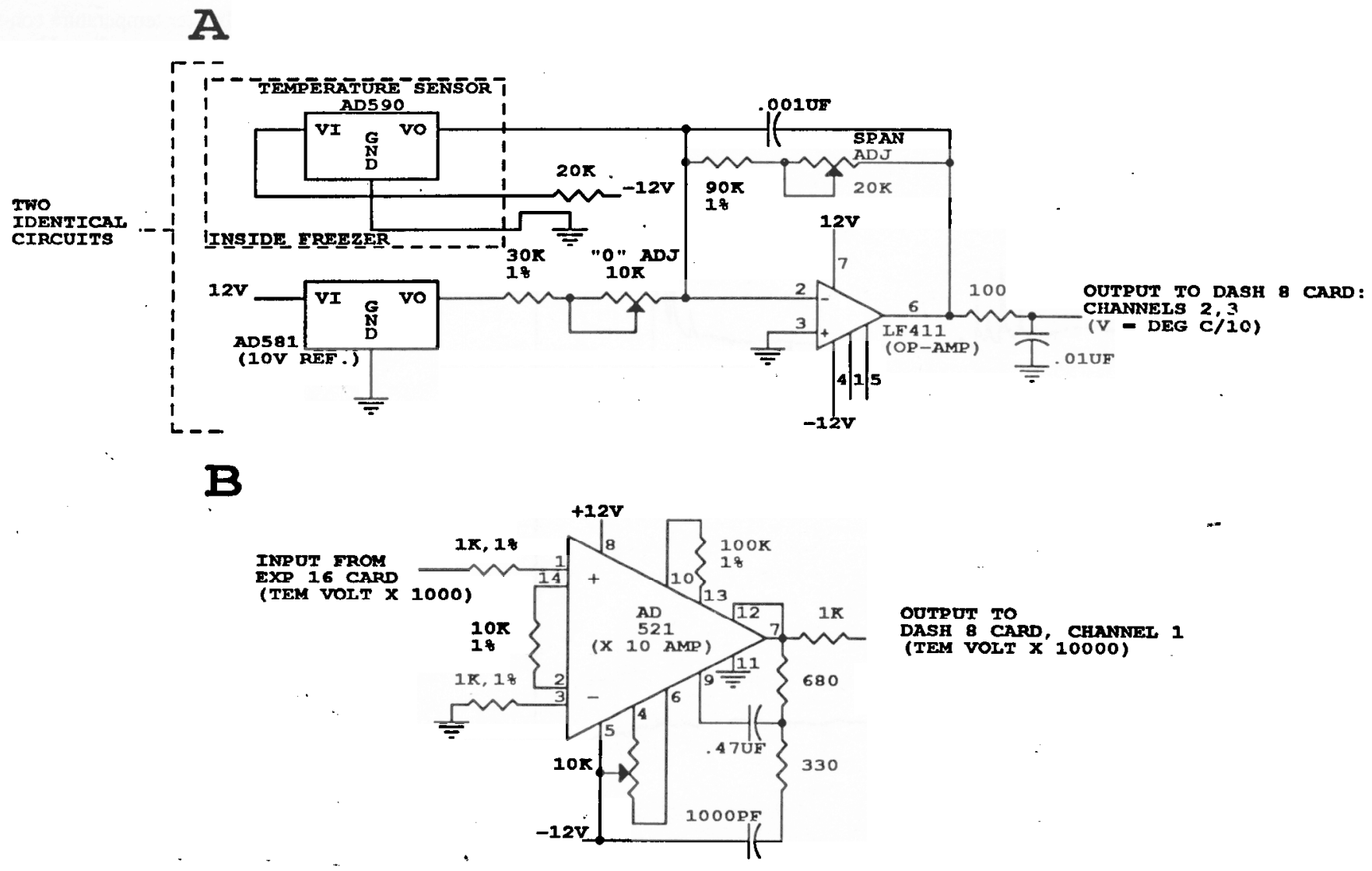

Fig. 2. Electrical diagram of the temperature-monitoring circuits (A) and the X10 amplifier (B) that were added to the EXP-16. (A) Two of these circuits are required to detect the temperature in the freezer compartment and the TEM chamber; the circuits are used to control the freezer compressor by the computer using the "COLLECTH" program. (B) The X10 amplifier for the thermoelectric module [TEM) output signal to the Dash-8 parallel interface card in the IBM-PC XT. The final signal output is amplified by 10,000 .

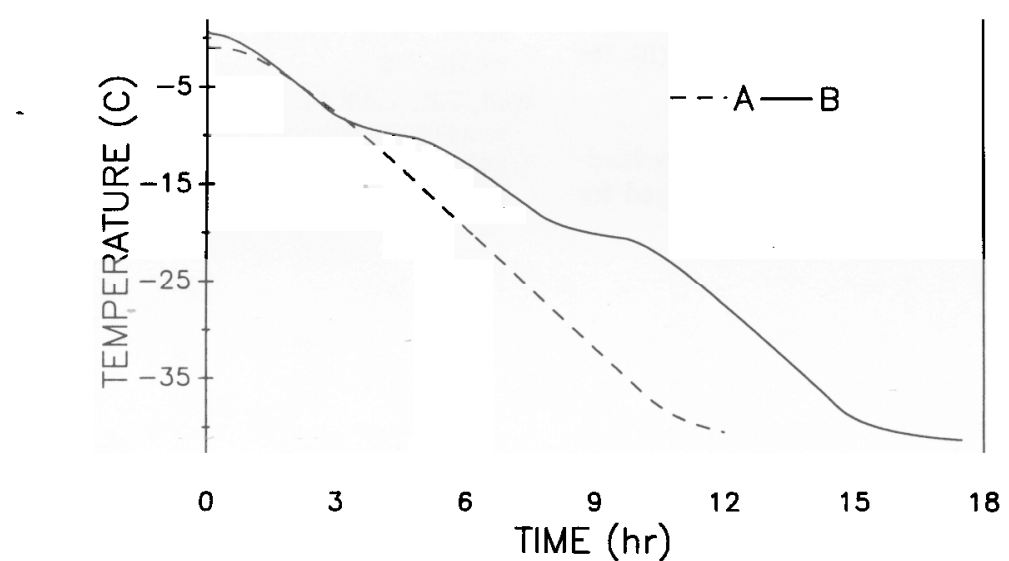

Fig. 3. (A) Profile of the temperature in the thermoelectric module (TEM) chamber programed for a decline of $-4 \mathrm{C} / \mathrm{hr}$ from 0 to $-40 \mathrm{C}$. (B) Temperature profile when programmed for 0 to $-10 \mathrm{C}$ in $2.5 \mathrm{hr},-10 \mathrm{C}$ for $2 \mathrm{hr},-10 \mathrm{to}-20 \mathrm{C}$ in $3 \mathrm{hr},-20 \mathrm{C}$ for $2 \mathrm{hr},-20$ to $-40 \mathrm{C}$ in $5 \mathrm{hr}$, and hold at $-40 \mathrm{C}$ for $2 \mathrm{hr}$.

for the TEM to pass through. The TEM was placed in contact with the bud side of the sample. Insulated cardboard was placed on the opposite side of, the TEM to equalize heat flux. Samples were placed in the TEM chamber and allowed to equilibrate at $\mathrm{OC}$.

Figure 4A represents an exotherm pattern for dormant 'Concord' grape buds. The nonlethal exotherms between -5 and $-10 \mathrm{C}$ are associated with extracellular water (Andrews et al., 1984) and are referred to as high-temperature exotherms. The exotherms between
-25 and $-30 \mathrm{C}$ represent intracellular ice formation in the buds and are considered lethal (Andrews et al., 1984) and confirmed by visual browning reactions (data not presented).

Exotherm analysis for two Russian wheat aphids (Diuraphis noxia apterous viviparae) is shown in Fig. 4B. Aphids were brought into contact with the TEM by first sticking them to cellophane tape and then taping them to the TEM. The short duration, lack of tailing, and size ( > $500 \mathrm{mV}$ ) give an indication of the sensitivity of the system. Aphids used for this experiment had an average weight of $624 \mu \mathrm{g}$ and contained $\approx 0.4 \mu \mathrm{l}$ of water

The temperature at which $50 \%$ of the specimens are killed $\left(\mathrm{LT}_{50}\right)$, estimated from the exotherm record, is taken as the temperature at which half of the total number of LTEs have occurred. The $\mathrm{LT}_{50}$ values determined with TEMs are within two degrees Celsius of those determined by visual analysis or tetrazolium tests (Andrews et al., 1984; Wolf and Pool, 1986). Increasing the number of specimens per TEM results in a better estimate of the population $\mathrm{LT}_{50}$.

Examples of computer exotherm analyses are presented as insets in Fig. $4 \mathrm{~A}$ and B. They show the temperatures at which two subsequent TEM data points varied by $100 \mathrm{mV}$ or more for the grape buds and by $500 \mathrm{mV}$ or more for the aphids. We have found $100 \mathrm{mV}$ to be a generally useful threshold value for exothenn analysis, but have used values as low as $50 \mathrm{mV}$ when the water content (and thus the size of the exotherms) has decreased. A comparison of exotherm analysis at 50- and $100-\mathrm{mV}$ threshold values for 'Cabernet Sauvignon', 'Chenin Blanc', and 'Concord' grape buds is presented in Table 1. Although the number of exotherms detected at $50 \mathrm{mV}$ increased, the estimated $\mathrm{LT}_{50}$ changed $<1 \mathrm{C}$, which indicates that selection of a threshold value is less critical than might be anticipated. These three examples are representative of thousands of samples run annually in our laboratory. The system presented represents sev- 

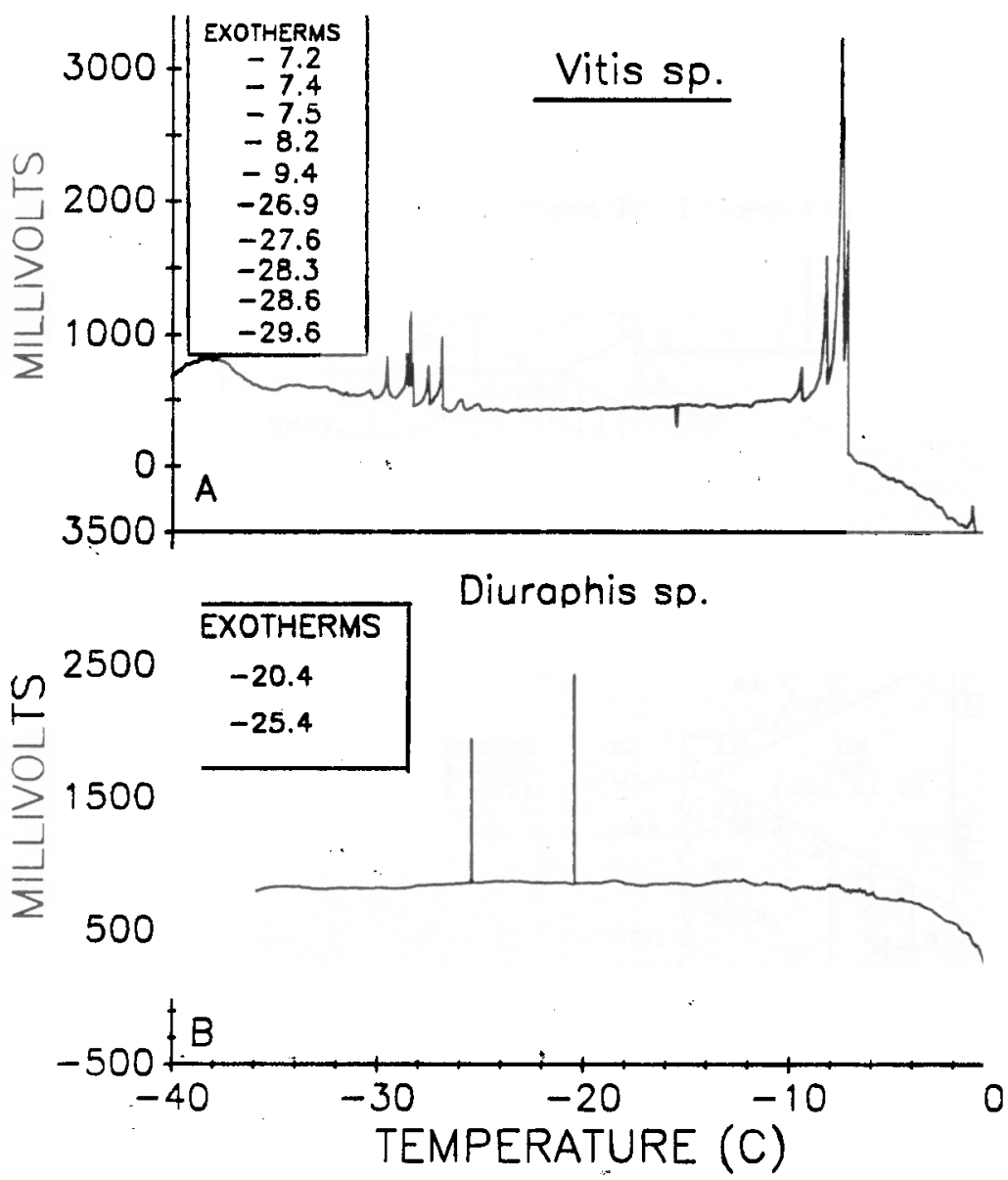

Fig. 4. (A) Exotherm profile for five 'Concord' grape buds placed on a single thermoelectric module (TEM) and the exotherm analysis (inset) performed at a threshold value of $100 \mathrm{mV}$ indicating the temperatures at which the high and low temperature exotherms occurred. (B) An exotherm profile for two aphids placed on a single TEM and the exotherm analysis (inset) performed at a threshold of $500 \mathrm{mV}$ indicating the temperatures at which the exotherms occurred. In botk(A) and (B), the rate of temperature change was $-4 \mathrm{C} / \mathrm{hr}$ from 0 to $-40 \mathrm{C}$.

eral improvements in the technology for the detection of LTEs and the subsequent evalu- ation of cold hardiness. The necessary hardware and software have been developed for customized, accurate freezer temperature control for low-temperature stress studies. Up to 80 simultaneous samples can be processed with software that collects and stores temperature files and exotherm data for analysis and longterm storage. Finally, software has been developed that is capable of evaluating these data, thereby minimizing the time required while increasing the consistency of the results.

Researchers interested in further details and copies of the software should contact the senior author.

\section{Literature Cited}

Andrews, P. K., E.L. Proebsting, and G.S. Campbell. 1983. An exotherm sensor for measuring the cold hardinesss of deep supercooled flower buds by differential thermal analysis. HortScience 18:7778

Andrews, P. K., C.R. Sandidge, and T.K. Toyama. 1984. Deep supercooling of dormant and deacclimating Vitis buds. Amer. J. Enol. Vitic. 35:175177.

Ashworth, E. N., G.W. Lightner, and D.J. Rowse. 1981. Evacuation of apricot flower bud hardiness using a computer-assisted method of thermal analysis. HortScience 16:754-756.

Burke, M.J., L.V. Gusta, H.A. Quamme, C.J. Weiser, and P.H. Li. 1976. Freezing injury in plants. Annu. Rev. Plant Physiol. 27:507-528.

Levitt, J. 1980. Responses of plants to environmental stresses. vol. 1 (2nd ed.). Academic, New York.

McLeester, R.C., C.J. Weiser, and T.C. Hall. 1969. Multiple freezing points as a test for viability of plant "stems in the determination of frost hardiness. Plant Physiol. 44:37-44.

Quamme, H.A. 1974. An exothermic process involved in the freezing injury of flower buds of several Prunus species. J. Amer. Soc. Hort. Sci. 99:315-318.

Wolf, T.K. and R.M. Pool 1986. Microcomputerbased data acquisition system for differential thermal analysis of grapevine dormant buds. HortScience 21:1447-1448. 